\title{
Recent cases of non-toxigenic Corynebacterium diphtheriae in Scotland: justification for continued surveillance
}

In recent years, there has been an increase in incidences of non-toxigenic Corynebacterium diphtheriae causing disease. Non-toxigenic strains generally cause persistent sore throats and severe pharyngitis/tonsillitis although complications of invasive disease such as endocarditis, septic arthritis, splenic abscesses and osteomyelitis are not uncommon (Wilson, 1995; Belko et al., 2000; von Hunolstein et al., 2002). Currently there is an overall lack of information on the prevalence of nontoxigenic $C$. diphtheriae colonization, prevalence and disease in the population due to a reduction in routine screening for this organism (Wagner et al., 2010). Here we describe three recent cases of non-toxigenic $C$. diphtheriae infection in Scotland and review the recent cases in the Grampian area.

\section{Case 1}

The patient was a 19-year-old female who presented with a persistent sore throat in January 2009. There were no underlying health problems or immunodeficiency and no recent travel history was reported. Throat swabs were incubated for 3 days on tellurite plates. Suspected C. diphtheriae colonies were then subcultured on to a Loeffler's serum slope, incubated for $14 \mathrm{~h}$ then examined for metachromatic granules using Albert's stain. The Streptococcus and Diphtheria Reference Laboratory (Health Protection Agency Streptococcus and Diphtheria Reference Unit at the Centre for Infections, Colindale, London, UK) confirmed the isolate for toxin production (toxin-negative) and assigned the biotype as gravis.

\section{Case 2}

The patient, a 25-year-old male from Poland who had been living in Scotland for 2 years, presented to the clinic with a persistent sore throat, cough and purulent cysts on his tonsils in January 2010. The patient was systemically well, reported no recent travel history, and had no known immunodeficiency. The immunization history of the patient was unclear. The isolate was treated as in Case 1 and was confirmed as biotype gravis and toxinnegative by the reference laboratory (Health Protection Agency Streptococcus and Diphtheria Reference Unit).

\section{Case 3}

The patient was a 22-year-old female from north-east Scotland. She presented with a persistent sore throat, intermittently inflamed and painful right tonsil and complained of chronic right nostril blockage in February 2010. The patient also had congenital cheiloschisis and palatoschisis. There was no recent travel history and the patient was immunized as a child and had no underlying immunodeficiency. The isolate was treated as in Case 1 and confirmed as biotype gravis and toxin-negative by the reference laboratory (Health Protection Agency Streptococcus and Diphtheria Reference Unit).

There was no known link between the three cases. All three isolates had identical morphologies on Trypticase Soy agar containing $5 \%$ sheep blood and Brain Heart Infusion agar. Their biochemical characteristics were confirmed using API Coryne (bioMérieux) and all strains were reconfirmed as $C$. diphtheriae biotype gravis. Antibiotic susceptibility testing was completed as prescribed by the Clinical and Laboratory Standards Institute (CLSI, 2006) on Mueller-Hinton agar containing $5 \%$ horse blood. All three strains were tested against and found to be susceptible to ampicillin $(10 \mu \mathrm{g})$, cefotaxime $(5 \mu \mathrm{g})$, ciprofloxacin $(1 \mu \mathrm{g})$, erythromycin $(15 \mu \mathrm{g})$, penicillin $\mathrm{G}$ (10 units), rifampicin $(5 \mu \mathrm{g})$ and tetracycline $(10 \mu \mathrm{g})$ by disc diffusion assay. All antibiotics were purchased from Oxoid.

\section{Recent cases}

A review of the cases of non-toxigenic $C$. diphtheriae isolated in the Grampian area (Aberdeen Royal Infirmary is responsible for a population of 500000 ) since 2002 revealed that there were 27 cases of $C$. diphtheriae infection. Only the last three isolates were available for characterization (see above). All were non-toxigenic isolates with $92 \%$ (25 cases) being C. diphtheriae biotype gravis, $4 \%$ (1 case) being $C$. diphtheriae biotype mitis and $4 \%$ (1 case) being $C$. diphtheriae biotype belfanti. All isolates of $C$. diphtheriae biotype gravis and biotype mitis were isolated from throat swabs with $92 \%(25 / 27)$ submitted by general practitioners, the remaining samples being taken from already hospitalized patients. All patients presenting symptoms were between 19 and 29 years old. The $C$. diphtheriae biotype belfanti isolate was obtained from blood cultures from a hospitalized patient. The 27 cases in 8 years in a population of 500000 indicates an incidence of 0.68 cases per 100000 of the Scottish population (total population 5 million). The UK Health Protection Agency (www.hpa.org. uk) suggests that 200-300 cases of nontoxigenic C. diphtheriae are seen each year in England and Wales (total population 52 million). At 300 cases, this equates to 0.58 cases per 100000 of the population, suggesting that infection rates are slightly higher in Scotland, or that current screening regimens underestimate incidences, especially given that not all hospitals in the UK screen routinely for $C$. diphtheriae from throat swabs (Wren \& Shetty, 2005). Wagner et al. (2010) have provided baseline carriage data across Europe for patients presenting with upper respiratory infections but further investigations into general carriage rates are still required.

\section{Discussion}

Since 1986, there has been a steady increase in the isolation of non-toxigenic $C$. diphtheriae in England and Wales, peaking at almost 300 cases in the year 2000 (compared 
to six cases of toxigenic diphtheria in the same year; www.hpa.org.uk). The majority of cases in Scotland were attributable to biotype gravis, as were strains from another UK study (De Zoysa et al., 2005). However, studies in France have found that biotype mitis is more prevalent (Patey et al., 1997), suggesting that our understanding of how biotypes are distributed within the population is lacking. Carriage rates in healthy individuals are poorly studied, with one study indicating that a high proportion of individuals may be asymptomatic carriers (Jephcott et al., 1975) whilst another suggests that asymptomatic carriage is low (Larsson et al., 1987). Such conflicting data make it difficult to determine the importance of carriage and the potential conversion from asymptomatic carriage to disease states. However, it is known that lysogenic conversion of non-toxigenic to toxigenic strains represents a significant threat in unimmunized individuals (Mokrousov, 2009; Simmons et al., 1980).

The mechanism of pathogenicity in nontoxigenic strains, however, is poorly understood; little is known of the genes responsible for colonization, invasion and survival in the host (Ott et al., 2010). There have been few studies to identify virulence loci outside of toxin production in $C$. diphtheriae, mainly due to the efficacy of the vaccine. However, this largely targets the diphtheria toxin and not the factors responsible for invasion and colonization, especially relevant for non-toxigenic $C$. diphtheriae. This is of particular importance due to the low levels of natural immunity ( $~ 50 \%)$ observed in UK populations from subclinical infections (Edmunds et al., 2000).

Recently, the strains in the cases reported here were isolated in the Grampian region, suggesting that disease caused by nontoxigenic C. diphtheriae may be rising. Our data indicate that incidences of disease are slightly higher than those reported for England and Wales, but may represent the continued screening of throat swabs at the Aberdeen Royal Infirmary, whilst many hospitals no longer screen. Wren \& Shetty (2005) found that $75 \%$ of isolates of $C$. diphtheriae sent for toxin testing in England and Wales originated from one laboratory, which suggests that a lack of screening is resulting in an underestimation of non-toxigenic $C$. diphtheriae infection rates. Indeed, it is tempting to speculate that many incidences of non-toxigenic $C$. diphtheriae infection are not recognized due to general practitioner treatment with standard broad-spectrum antibiotics and no further complications being observed, suggesting that the number of cases is significantly underestimated.

Given that there is a potential lack of recognition of non-toxigenic $C$. diphtheriae infection by healthcare professionals and the prediction that non-toxigenic $C$. diphtheriae is an emerging pathogen of increasing significance worldwide (Gomes et al., 2009; Mokrousov, 2009; Reacher et al., 2000), it is suggested that there is an urgent need for increased clinical awareness, especially in immunocompromised patients where complications can arise (Wilson, 1995; Belko et al., 2000; von Hunolstein et al., 2002). It is therefore paramount that a greater understanding of the mechanisms of nasopharyngeal carriage/invasion, the incidence rates, strain variation and population structure of non-toxigenic $C$. diphtheriae is obtained.

\section{Becky Edwards, ${ }^{1}$ Alison C. Hunt ${ }^{2}$ and Paul A. Hoskisson ${ }^{3}$}

${ }^{1}$ Medical Microbiology \& Virology, Aberdeen Royal Infirmary, Foresterhill, Aberdeen AB25 2ZN, UK

${ }^{2}$ Department of Microbiology, Royal Infirmary of Edinburgh, 51 Little France Crescent, Edinburgh EH16 4SA, UK

${ }^{3}$ Strathclyde Institute of Pharmacy and Biomedical Science, University of Strathclyde, 161 Cathedral Street, Glasgow G4 ORE, UK

\section{Correspondence: Paul A. Hoskisson (paul.hoskisson@strath.ac.uk)}

Belko, J., Wessel, D. L. \& Malley, R. (2000). Endocarditis caused by Corynebacterium diphtheriae: case report and review of the literature. Pediatr Infect Dis J 19, 159-163.

CLSI (2006). Methods for Antimicrobial Dilution and Disk Susceptibility Testing of Infrequently Isolated or Fastidious Bacteria; Approved Guideline. M45-A. Wayne, PA: Clinical and Laboratory Standards Institute.

De Zoysa, A., Efstratiou, A. \& Hawkey, P. M. (2005). Molecular characterization of diphtheria toxin repressor $(d t x R)$ genes present in nontoxigenic Corynebacterium diphtheriae strains isolated in the United Kingdom. J Clin Microbiol 43, 223-228.

Edmunds, W. J., Pebody, R. G., Aggerback, H., Baron, S., Berbers, G., Conyn-van Spaendonck, M. A., Hallander, H. O., Olander, R., Maple, P. A. \& other authors (2000). The sero-epidemiology of diphtheria in Western Europe. Epidemiol Infect 125, 113-125.

Gomes, D. L., Martins, C. A., Faria, L. M., Santos, L. S., Santos, C. S., Sabbadini, P. S., Souza, M. C., Alves, G. B., Rosa, A. C. \& other authors (2009). Corynebacterium diphtheriae as an emerging pathogen in nephrostomy catheter-related infection: evaluation of traits associated with bacterial virulence. J Med Microbiol 58, 1419-1427.

Jephcott, A. E., Gillespie, E. H., Davenport, C., Emerson, J. W. \& Moroney, P. J. (1975). Nontoxigenic Corynebacterium diphtheriae in a boarding school. Lancet 1, 1025-1026.

Larsson, P., Brinkhoff, B. \& Larsson, L. (1987). Corynebacterium diphtheriae in the environment of carriers and patients. J Hosp Infect 10, 282-286.

Mokrousov, I. (2009). Corynebacterium diphtheriae: genome diversity, population structure and genotyping perspectives. Infect Genet Evol 9, 1-15.

Ott, L., Höller, M., Gerlach, R. G., Hensel, M., Rheinlaender, J., Schäffer, T. E. \& Burkovski, A. (2010). Corynebacterium diphtheriae invasionassociated protein (DIP1281) is involved in cell surface organization, adhesion and internalization in epithelial cells. BMC Microbiol 10, 2.

Patey, O., Bimet, F., Riegel, P., Halioua, B., Emond, J. P., Estrangin, E., Dellion, S., Alonso, J. M., Kiredjian, M. \& other authors (1997). Clinical and molecular study of Corynebacterium diphtheriae systemic infections in France. J Clin Microbiol 35, 441-445.

Reacher, M., Ramsay, M., White, J., De Zoysa, A., Efstratiou, A., Mann, G., Mackay, A. \& George, R. C. (2000).

Nontoxigenic Corynebacterium diphtheriae: an emerging pathogen in England and Wales? Emerg Infect Dis 6, 640-645.

Simmons, L. E., Abbott, J. D., Macaulay, M. E., Jones, A. E., Ironside, A. G., Mandal, B. K., Stanbridge, T. N. \& Maximescu, P. (1980). Diphtheria carriers in Manchester: simultaneous infection with toxigenic and non-toxigenic mitis strains. Lancet 1, 304-305.

von Hunolstein, C., Scopetti, F., Efstratiou, A. \& Engler, K. (2002). Penicillin tolerance amongst non-toxigenic Corynebacterium diphtheriae isolated from cases of pharyngitis. J Antimicrob Chemother 50, 125-128.

Wagner, K. S., White, J. M., Neal, S., Crowcroft, N. S., Kuprevičiene, N., Paberza, R., Lucenko, I., Jõks, U., Akbaş, E. \& other authors (2010).

Screening for Corynebacterium diphtheriae and Corynebacterium ulcerans in patients with upper respiratory tract infections 2007-2008: a multicentre European study. Clin Microbiol Infect. doi: 10.1111/j.1469-0691.2010.03269.x

Wilson, A. P. (1995). The return of Corynebacterium diphtheriae: the rise of nontoxigenic strains. J Hosp Infect 30, S306-S312.

Wren, M. W. \& Shetty, N. (2005).

Infections with Corynebacterium diphtheriae: six years' experience at an inner London teaching hospital. Br J Biomed Sci 62, 1-4. 